\title{
Research of the Software Design Curriculum System Based on CDIO
}

\author{
Li Zhao \\ School of Computer Science and Engineering, \\ Xi'an Technological University, \\ Xi'an , China \\ e-mail:zhaoli1998@163.com \\ Yaxin Zhao \\ School of Computer Science and Engineering, \\ Xi'an Technological University, \\ Xi'an , China \\ e-mail:953383250@qq.com
}

\author{
Yan Hui \\ School of Computer Science and Engineering, \\ Xi'an Technological University, \\ Xi'an, China \\ e-mail:6591127@qq.com
}

\begin{abstract}
The software design and development capability is one of the most important professional ability of students who studied computer and related professional. This paper analyses the existing condition of the software design class core curriculum. It lacks of organic integration among courses in the teaching. and influences the capability of software design. Based on CDIO concept, build the Software design core curriculum architecture based on ability culture orientation .It combines two levels of curriculum system with three phase of software design ability, building a blended learning teaching model based on different platforms. In order to strengthen the cultivation of student's ability of software design and improve the ability of practice and innovation.
\end{abstract}

Keywords:Software Design Courses; CDIO; Blended Learning

\section{INTRODUCTION}

CDIO is a new education idea and implementary system developed jointly by three universities including the Massachusetts institute of technology in US, mustang technology university In Sweden, linkoping university and the royal institute of technology in2001.CDIO is the meaning of "Conceive""Design" "Implement""Operate". CDIO engineering education pay attention to cultivate the students to master the solid basic theory and professional knowledge, and put the education process to the specific situation in the field of engineering. Through team design of the whole talent training process and innovative practice training. It cultivates good professional basis, high level engineers. CDIO views life cycle from product research to product operation as the carrier. Let students study engineering in an active, hands-on, and organically connected way. The education mode of CDIO engineering emphasizes the idea of integrated construction, that is, all links are organically linked together. The software design and software development ability of students is the important aspect of computer related professional students' professional quality. The software design and software development ability of students is the important aspect of computer related professional students' professional quality. The software design class courses are variety. There are many kinds of software design courses and many directions in the development technology. The problem of courses is lack of organic integration. These influence the formation of students' capabilities of the software design.

In this paper we analyze and cultivate teaching rule of Software design capability. On the basis of course inner link building software design class curriculum system. Discussing different stages teaching contents and teaching methods of cultivating the ability of software design. Around the disadvantages of Core courses in software design including target location, teaching content, teaching model, etc. We propose to ability oriented and build software design class core curriculum teaching system. Optimizing the teaching contents and reforming the teaching mode. In order to better cultivate 
students programming ability, improve their practice and innovation ability.

\section{THE CONSTRUCTION OF CORE CURRICULUM SYSTEM IN SOFTWARE DESIGN CLASS}

In my university, the core courses of institute of computer in software design including core courses for the $\mathrm{C}$ language program design, Java language object-oriented program design, object-oriented $\mathrm{C}++$ program design, algorithm and data structure, algorithm design and analysis, component technology (Java), mobile application development, web applications and database principles and applications, etc.

In the teaching process, we found that although the students to learn a variety of programming languages, but learning is not good. A lot of courses are studied but classes are isolated. This lacks of organic connection. There is no clear and complete curriculum system structure of software design. Based on CDIO concept, therefore, we need to build core courses architecture for software design based on ability culture orientation we link up organically software design curriculum set in different phases. and aiming at different stages, we design the corresponding teaching target, teaching methods and evaluation standards. To change the traditional teaching plan on the basis of courses. we use the knowledge structure of professional education as the foundation and carrier. Emphasizing the basic professional knowledge at the same time, emphasis on compaction of capability foundation. Building Continuity, mutual echo and gradually deepened software design class curriculum system, cultivating the students' ability of sustainable development.

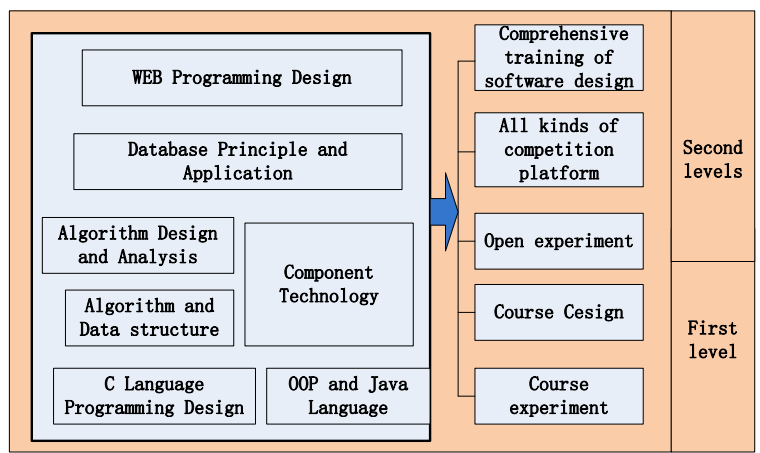

Figure 1. Software design class system

After several years of exploration and research, we build the curriculum teaching target system is oriented by the ability of culture, as shown in figure 1.Through reform and optimize the teaching content, emphasize knowledge coherence between the course of each course. We establish a teaching system. According to the curriculum teaching target system. The curriculum content system is designed by the teachers in curriculum groups together. It is gradually increase, coherent, layer upon layer gradient propulsion system .Starting from the basic course of program design, we introduce a large number of classic, interesting thick, contact life actual case, to guide students to solve problems, learn programming knowledge and statements, and to improve their interest in programming. At the same time, the teaching case design pay attention to the comprehensive and consistency of knowledge before and after, In front of the Classes, methods, or modules of design and implementation is the groundwork for subsequent cases. Developing students' consciousness of systematic, in order to help students to establish knowledge system.

Secondly, emphasizing the hierarchy of curriculum system. The importance of software design ability has been recognized in all aspects. We have divided the cultivation of software design ability into three stages. Early stage: primary programming and implementation capacity training. Middle stage: the cultivation of algorithm analysis and design ability. Late stage: the training of system analysis ability. The training of these three stages corresponds to the two levels of the curriculum system. The first level is the basic level of $\mathrm{C}$ language programming, object-oriented Java programming, algorithm and data structure, algorithm design and analysis course. In the first level, the basic thought of integration of 
curriculum group construction is through in-class experiment, curriculum design, the open experiment three link, based on the knowledge of high level language program design, strengthen language training and algorithm design. The second level is the combination of component technology (Java), mobile application development, web application development, database principle and application of curriculum knowledge, more emphasis on the integration of theory with practice. Through software integrated course design, production practice and other links, the understanding and solution of complex problems are strengthened, and the cultivation of system analysis ability is emphasized.

\section{BUILD A TEACHING MODEL OF HYBRID LEARNING BASED ON DIFFERENT PLATFORMS}

The software design class has a strong practicability, which puts forward higher requirements for classroom learning and after-school training.Blended Learning organically combined with traditional classroom Learning and the way of digital Learning.In software design class teaching, we combined with the "flip the classroom teaching", "open experiment" and "college students competition" and so on the platform and way, around the "two levels"ofcourse system and the "three stage" of software design to cultivate goals. According to the enlightenment introduction of program design ability, the teaching characteristics of different stages are developed and applied. From the blended learning teaching method, classroom experiment, curriculum design and "open experiment" diversified software design activities to organize strategy, under support of the competition platform of college students in multistage and various links of teaching evaluation, we study on the exploration of blended learning.

Inverted Classroom, which originated in the Colorado woodland park high school, refers to re-adjusting the time inside and outside the Classroom, transferring the decision of learning from the teacher to the student. The knowledge points of the class are taught by students outside the class, and then discussed in class by the group.
The teacher can solve the problem to complete the internalization of knowledge. In this way, students can concentrate more on active learning and gain a deeper understanding. Inverted Classroom upside-down the knowledge and internalization of knowledge in traditional classroom. It is a powerful means for teachers and students to interact and stimulate their interest in learning. Inverted Classroom provides environment and platform for the discussion of teaching and project-driven teaching, which truly reflects the education concept of "students as the center". At present, with the help of the school "learning through" teaching platform, it is carrying out the flipped classroom teaching of design classes such as data structure and Java language.

Before class, students learn, practice and think through video provided by the teacher. In class, guide students to study software design process. Students generally reflect that this kind of teaching mode can arouse the enthusiasm of learning.

In the practice teaching link, in addition to in-class experiment and curriculum design of the teaching plan, we opened for all college students "software algorithm design" and so on the many kinds of design class open experiment. With the help of the school competition platform which is acm.xatu.edu.cn and the third party competition platform which is https://pintia.cn/, the open experiment practice and the school "software algorithm design competition" was launched. Integrating the competition subject of ACM programming contest, blue cup software design competition of talents and the China cup university student design competition into in-class experiment and curriculum design related to software design curriculum.To integrate the assessment methods of related competitions and submission requirements into the assessment requirements of relevant integrated software design experiments. This enables practical teaching through the whole process of teaching, and develops software talents with real software analysis and design ability. And cultivate students' ability of sustainable development.

\section{CONCLUSION}

In the research of this topic, we realize that the cultivation of software design ability is a gradual process of "two levels" and "three stages".According to the teaching rules of software 
design ability, we build the core curriculum system of software design. For different stages, different teaching methods and teaching modes are adopted based on different platforms.To stimulate students' active initiative, it has achieved better results in teaching practice.

\section{ACKNOWLEDGMENT}

Fund projects:(1) Research project on teaching reform of online open courses in Shannxi universities (16MY19); (2)Teaching reform project of Xi'an Technological University (15JGY13) (16JGY24).

\section{REFERENCES}

[1] Wang Shuowang, Hong chengwen. CDIO: the classic model of education in MIT engineering [J]. Polytechnic research, 2009 (8) : 116-119

[2] Li Chunlian, Yang Liping. A study on the teaching strategies of program design under CDIO concept [J]. Journal of Changchun university. 2016(4):87-89

[3] Qin Zunyue, etc. Software engineering professional Java language teaching reform based on CDIO concept [J]. Computer education, 2012 (19) : 77-81

[4] Zhao lijuan, Liu Fanhua, etc. Study on the effect of design method of computer software class learning activities based on "Inverted Classroom" [J]. Education information technology 2015 (4) 17-21

[5] LI Junxian.The Peliminary Study on "Flipped Classroom+" Applied in Software Engineering Course [J].Educationteaching forum. 2017 (9) :116-117 